\title{
Costimulation Blockade with Belatacept in Renal Transplantation
}

\author{
Flavio Vincenti, M.D., Christian Larsen, M.D., Ph.D., Antoine Durrbach, M.D., Ph.D., \\ Thomas Wekerle, M.D., Björn Nashan, M.D., Ph.D., Gilles Blancho, M.D., Ph.D., \\ Philippe Lang, M.D., Josep Grinyo, M.D., Philip F. Halloran, M.D., Ph.D., \\ Kim Solez, M.D., David Hagerty, M.D., Elliott Levy, M.D., Wenjiong Zhou, Ph.D., \\ Kannan Natarajan, Ph.D., and Bernard Charpentier, M.D., \\ for the Belatacept Study Group*
}

\section{ABSTRACT}

\section{BACKGROUND}

From the University of California, San Francisco, San Francisco (F.V.); the Emory Transplant Center and Department of Surgery, Emory University School of Medicine, Atlanta (C.L.); the Nephrology Unit, INSERM Unité 542, Le Kremlin Bicêtre Hospital, Le Kremlin Bicêtre, France (A.D., B.C.); the Department of Surgery, Division of Transplantation, Vienna General Hospital, Medical University of Vienna, Vienna (T.W.); Klinik für Viszeral- und Transplantationschirurgie, Medizinische Hochschule Hannover, Han nover, Germany (B.N.); the Nephrology Unit, Hotel Dieu Hospital, Nantes, France (G.B.); Service de Néphrologie et de Transplantation, Hôpital Henri-Mondor, Créteil France (P.L.); the Department of Medicine, Universitat de Barcelona, Hospital Universitari de Bellvitge, Barcelona (J.G.); the Departments of Medicine (P.F.H.) and Laboratory Medicine and Pathology (K.S.) University of Alberta, Edmonton, Alta., Canada; and Bristol-Myers Squibb Pharmaceutical Research Institute, Princeton, N.J. (D.H., E.L., W.Z., K.N.). Address reprint requests to Dr. Larsen at Emory University, Rm. 5105 WMB, 1639 Pierce Dr., Atlanta, GA 30322, or at clarsen@emory.org.

Drs. Vincenti and Larsen contributed equally to the article.

*Additional members of the Belatacept Study Group are listed in the Appendix.

N Eng|J Med 2005;353:770-81.

Copyright @ 2005 Massachusetts Medical Society.
Renal transplantation is the standard of care for patients with end-stage renal disease. Although maintenance immunosuppression with calcineurin inhibitors yields excellent one-year survival, it is associated over the long term with high rates of death and graft loss, owing in part to the adverse renal, cardiovascular, and metabolic effects of these agents. The use of potentially less toxic agents, such as belatacept, a selective blocker of T-cell activation, may improve outcomes.

\section{METHODS}

We randomly assigned renal-transplant recipients to receive an intensive or a lessintensive regimen of belatacept or cyclosporine. All patients received induction therapy with basiliximab, mycophenolate mofetil, and corticosteroids. The primary objective was to demonstrate the noninferiority of belatacept over cyclosporine in the incidence of acute rejection at six months (with an upper bound of the 95 percent confidence interval around the treatment difference of less than 20 percent).

RESULTS

At six months, the incidence of acute rejection was similar among the groups: 7 percent for intensive belatacept, 6 percent for less-intensive belatacept, and 8 percent for cyclosporine. At 12 months, the glomerular filtration rate was significantly higher with both intensive and less-intensive belatacept than it was with cyclosporine $(66.3,62.1$, and $53.5 \mathrm{ml}$ per minute per $1.73 \mathrm{~m}^{2}$, respectively), and chronic allograft nephropathy was less common with both regimens of belatacept than with cyclosporine ( 29 percent, 20 percent, and 44 percent, respectively). Lipid levels and blood-pressure values were similar or slightly lower in the belatacept groups, despite the greater use of lipidlowering and antihypertensive medications in the cyclosporine group.

\section{CONCLUSIONS}

Belatacept, an investigational selective costimulation blocker, did not appear to be inferior to cyclosporine as a means of preventing acute rejection after renal transplantation. Belatacept may preserve the glomerular filtration rate and reduce the rate of chronic allograft nephropathy. 
$\mathrm{R}$

ENAL TRANSPLANTATION, THE STANdard of care for patients with end-stage renal disease, improves survival and the quality of life. ${ }^{1-4}$ Current regimens of immunosuppression yield excellent one-year rates of patient and graft survival; however, five-year survival rates among recipients of kidneys from cadaveric donors and living related donors are only 66 percent and 79 percent, respectively. ${ }^{5}$ Paradoxically, the commonly used calcineurin inhibitors, effective for immunosuppression, contribute to late allograft loss and death. Calcineurin inhibitors are nephrotoxic and have adverse effects on blood pressure, lipid levels, and glucose homeostasis.6,7 Thus, calcineurin inhibitors promote cardiovascular disease, the most common cause of death among transplant recipients, as well as chronic allograft nephropathy, the most common cause of late graft loss among surviving patients. ${ }^{8,9} \mathrm{~A}$ current challenge in renal transplantation is to develop immunosuppressive regimens that protect against rejection as well as calcineurin inhibitors do but without the adverse renal and cardiovascular effects.

Belatacept (LEA29Y), a selective costimulation blocker, binds surface costimulatory ligands (CD80 and CD86) of antigen-presenting cells. In the context of antigen recognition (signal 1), the interaction of CD80 and CD86 with the surface costimulatory receptor $\mathrm{CD} 28$ of $\mathrm{T}$ cells (signal 2) is required for full activation of $\mathrm{T}$ cells. Blockade of signal 2 inhibits T-cell activation, promoting anergy and apoptosis. ${ }^{10}$ Belatacept was derived from abatacept, a human fusion protein combining the extracellular portion of cytotoxic T-lymphocyte-associated antigen 4 (CTLA4) with the constant-region fragment $(\mathrm{Fc})$ of human IgG1 (CTLA4Ig). Although abatacept is an efficacious treatment for T-cellmediated autoimmune disorders, such as rheumatoid arthritis ${ }^{11}$ and psoriasis, ${ }^{12}$ it is an ineffective means of prophylaxis against rejection in nonhuman primate models of transplantation. ${ }^{13}$ Belatacept differs from abatacept by two specific aminoacid substitutions, thus conferring greater binding avidity to CD80 and CD86, more potent inhibition of T-cell activation, and effective rejection prophylaxis in nonhuman primates. ${ }^{14}$ The primary objective of this study was to demonstrate the noninferiority of belatacept over cyclosporine with respect to the incidence of biopsy-proven acute rejection at six months.
METHODS

\section{DESIGN}

The study was a partially blinded, randomized, parallel-group, multicenter, phase 2 study with an active control and was conducted at 22 centers in the United States, Canada, and Europe between March 2001 and December 2003. Drs. Hagerty, Vincenti, Larsen, and Charpentier designed the protocol and the trial. Drs. Vincenti, Larsen, Durrbach, Wekerle, Nashan, Lang, Grinyo, Halloran, Solez, Blancho, and Charpentier as well as other members of the Belatacept Study Group collected data. Data were analyzed and primarily vouched for by Drs. Zhou, Natarajan, Nashan, Levy, Halloran, Vincenti, Larsen, and Charpentier and reviewed by all other authors. The manuscript was written by Drs. Levy, Vincenti, Larsen, and Charpentier and critically reviewed and revised by the other authors. The data were held by Bristol-Myers Squibb. A data and safety monitoring board assessed overall safety in an unblinded fashion with the use of reports of adverse events and laboratory results.

\section{SUBJECTS}

Adult recipients of a renal allograft from a nonHLA-identical living or deceased donor were eligible. Patients who had previously undergone renal transplantation, patients with a history of a panelreactive antibody titer exceeding 20 percent, and patients deemed at increased risk for acute rejection by an investigator could make up no more than 10 percent of the study population and were considered higher-risk patients. The following characteristics were exclusion criteria: underlying renal disease in the recipient that could recur in the allograft, including focal and segmental glomerulosclerosis, type I or II membranoproliferative glomerulonephritis, the hemolytic-uremic syndrome, and thrombotic thrombocytopenic purpura; active hepatitis B or C or any other infection that would normally preclude transplantation; human immunodeficiency virus infection; a history of or evidence of cancer; a positive T-cell lymphocytotoxic crossmatch with the use of donor lymphocytes and recipient serum; a history of drug or alcohol abuse or psychotic disorders; previous treatment with basiliximab; use of any investigational drug within 30 days before the visit on day 1 ; a donor age of more than 60 years or less than 6 years; a donor whose 
heart was not beating at the time of organ harvest; and a cold-ischemia time of more than 36 hours.

\section{END POINTS}

The primary objective was to demonstrate that belatacept was not inferior to cyclosporine in its ability to prevent rejection at six months. Acute rejection, defined clinicopathologically, required an increase in the serum creatinine level of at least $0.5 \mathrm{mg}$ per deciliter ( $44.2 \mu \mathrm{mol}$ per liter) over prerejection baseline levels in the absence of other confounding factors and findings on renal biopsy consistent with the presence of acute rejection (as defined by the Banff 97 criteria for classifying renal-transplant biopsy specimens). ${ }^{15}$ Patients who had had one episode of rejection by month 6 were considered to have reached the primary end point. A sensitivity analysis was performed with the use of less stringent clinical criteria (an increase in serum creatinine levels of at least $0.3 \mathrm{mg}$ per deciliter [ $26.5 \mu \mathrm{mol}$ per liter]). Subclinical rejection was defined by findings on renal biopsy consistent with the presence of acute rejection (according to the Banff 97 criteria), without an increase in the serum creatinine level of at least $0.5 \mathrm{mg}$ per deciliter.

Secondary end points were the incidence of acute rejection (biopsy-confirmed or presumed) at 6 months and 1 year; the measured glomerular filtration rate, as determined by iohexol clearance, at 1,6 , and 12 months; the prevalence of hypertension; serum cholesterol and triglyceride levels; and overall safety. Other prespecified analyses included the rate of death or graft loss at one year; the incidence of post-transplantation diabetes mellitus (defined as the need for therapy for hyperglycemia for at least four weeks or a glycosylated hemoglobin value greater than 7 percent in patients not previously known to have diabetes); the calculated glomerular filtration rate, as determined by the Modification of Diet in Renal Disease method, ${ }^{16}$ the Jelliffe formula, ${ }^{17}$ the Cockcroft-Gault equation, ${ }^{18}$ and the Nankivell formula ${ }^{19}$; pharmacokinetics; and immunogenicity. A post hoc analysis was conducted of the incidence of chronic allograft nephropathy (according to the Banff 97 criteria). In addition, a post hoc analysis of patients who had treatment for hypertension was performed during the 12 months of follow-up.

\section{NTERVENTIONS}

Patients were randomly assigned in equal numbers to receive an intensive regimen of belatacept, a less-intensive regimen of belatacept, or cyclosporine (Neoral, Novartis) for primary maintenance immunosuppression (Fig. 1). Randomization was performed centrally. Both belatacept regimens included an early phase (10 mg of belatacept per kilogram of body weight) and a late phase (5 mg of belatacept per kilogram at four-week or eight-week intervals). Doses, based on body weight, were dictated by trough profiles shown to be effective in studies of nonhuman primates. This approach necessitated the use of higher doses during the period of greatest immunologic risk (day 0 through day 90 ). The early phase was longer in the intensive regimen (six months vs. three months) and included more frequent dosing. Belatacept was administered as a 30-minute intravenous infusion. The dose of cyclosporine was chosen to achieve prespecified ranges of serum levels (Fig. 1). Because of the requirement for therapeutic monitoring and adjustments in dose, cyclosporine was administered in an unblinded fashion.

All patients received induction therapy with $20 \mathrm{mg}$ of basiliximab (Simulect, Novartis) on day 0 and day 4, $2 \mathrm{~g}$ of mycophenolate mofetil (CellCept, Roche) daily, and a corticosteroid-tapering regimen, consisting of an intravenous bolus of $500 \mathrm{mg}$ of methylprednisolone on day 1 and $250 \mathrm{mg}$ on day 2 , followed by $100 \mathrm{mg}$ of oral prednisone on day 3, $50 \mathrm{mg}$ on day 4, $25 \mathrm{mg}$ on days 5 through 30 , $22.5 \mathrm{mg}$ on days 31 through $44,20 \mathrm{mg}$ on days 45 through $58,17.5 \mathrm{mg}$ on days 59 through $72,15 \mathrm{mg}$ on days 73 through $86,12.5 \mathrm{mg}$ on days 87 through 100 , and $10 \mathrm{mg}$ on days 101 through 114 . After day 114 , the dose could be decreased by $2.5 \mathrm{mg}$ every other month but not to less than $5 \mathrm{mg}$ per day.

Episodes of acute rejection of Banff 97 grade IIA or less were treated with bolus corticosteroids. Corticosteroid-resistant episodes or episodes of at least grade IIB were treated with antibody therapy.

\section{RENAL BIOPSY AND MEASUREMENT OF GLOMERULAR FILTRATION RATE}

Renal biopsy was performed at baseline (intraoperatively) and at month 12 . Additional biopsy specimens were obtained as needed to diagnose acute rejection and to evaluate a patient's response to antirejection therapy. All biopsy specimens were examined locally as well as centrally by a single histopathologist according to Banff 97 criteria in a blinded fashion. Results of the central interpretation were used for all analyses.

The glomerular filtration rate was measured at 
months 1,6 , and 12 by determining the rate of disappearance from the plasma of a 5 -ml bolus of unlabeled iohexol over a period of four hours. Samples were analyzed at a central facility. The glomerular filtration rate was estimated with the use of the formulas mentioned above.

\section{STATISTICAL ANALYSIS}

Primary efficacy analyses were performed according to the intention to treat with the use of data from all patients who underwent randomization and transplantation. The primary efficacy variable was summarized within and between treatment groups with the use of point estimates and 95 percent confidence intervals. For the primary efficacy end point, the upper bound of the 95 percent confidence interval around the treatment difference had to be less than 20 percent for belatacept to be considered noninferior to cyclosporine. Assuming a 15 percent rate of clinically suspected, biopsy-proven episodes of acute rejection and a 10 percent dropout rate, we determined that 70 patients were required in each treatment group for the study to have a statistical power of 85 percent. For other analyses, no statistical hypotheses were prespecified, and descriptive summaries are provided.

\section{RESULTS}

\section{CHARACTERISTICS AND DISPOSITION OF THE PATIENTS}

A total of 218 patients underwent randomization and transplantation: 74 were assigned to receive intensive belatacept, 71 to receive less-intensive belatacept, and 73 to receive cyclosporine. Two patients assigned to receive cyclosporine did not receive a single dose and thus were not included in safety analyses. Baseline demographic and clinical characteristics were similar among the groups (Table 1). The rates of discontinuation were also similar: 16 patients discontinued intensive belatacept, 16 discontinued less-intensive belatacept, and 20 discontinued cyclosporine. A total of 164 patients completed one year of treatment.

\section{ACUTE REJECTION}

The incidence of acute rejection at six months was similar among the groups and satisfied noninferiority criteria as predefined: 7 percent in the group receiving-intensive belatacept, 6 percent in the group receiving less-intensive belatacept, and 8 percent in the cyclosporine group (absolute difference

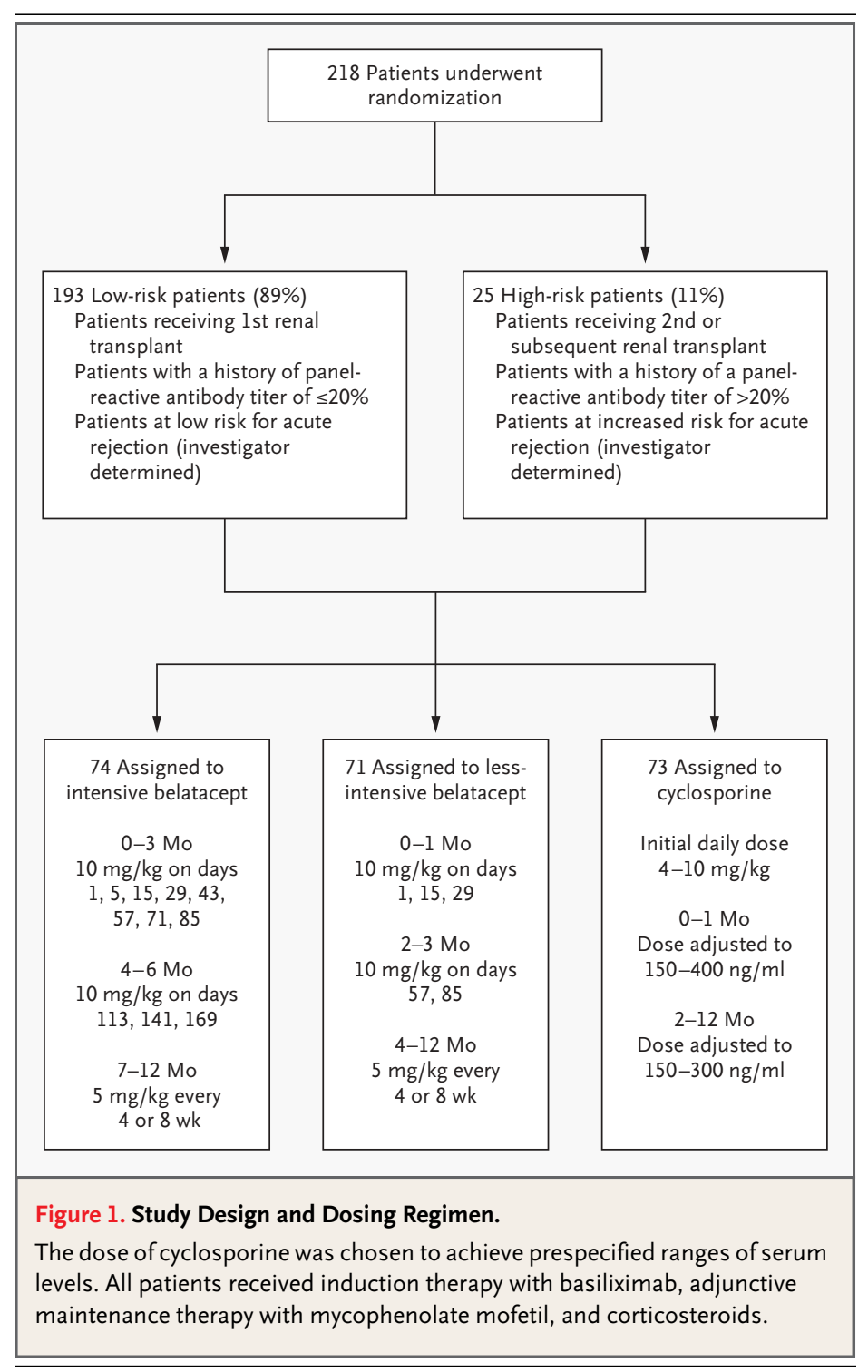

between intensive therapy and cyclosporine, -1.5 percentage points [95 percent confidence interval, -11.3 to 8.3 percentage points], and absolute difference between less-intensive therapy and cyclosporine, -2.6 percentage points [ 95 percent confidence interval, -12.3 to 6.7 percentage points]) (Table 2). No episodes of acute rejection were reported after month 6 in any group. Episodes of rejection were more frequent when an increase in the serum creatinine level of at least $0.3 \mathrm{mg}$ per deciliter was used as a criterion, but the incidence was similar among the groups ( 9 percent in the group receiving intensive belatacept, 8 percent in the group receiving less-intensive belatacept, and 11 percent in the cyclosporine group). Episodes of rejection 


\begin{tabular}{|c|c|c|c|}
\hline Characteristic & $\begin{array}{c}\text { Intensive Belatacept } \\
\quad(\mathrm{N}=74)\end{array}$ & $\begin{array}{l}\text { Less-Intensive Belatacept } \\
\qquad(\mathrm{N}=71)\end{array}$ & $\begin{array}{l}\text { Cyclosporine } \\
(\mathrm{N}=73)\end{array}$ \\
\hline Age $(y r) \dagger$ & 46.5 & 42.1 & 46.1 \\
\hline \multicolumn{4}{|l|}{$\operatorname{Sex}(\%)$} \\
\hline Male & 73 & 68 & 67 \\
\hline Female & 27 & 32 & 33 \\
\hline \multicolumn{4}{|l|}{ Race or ethnic group $(\%) \ddagger$} \\
\hline White & 86 & 80 & 81 \\
\hline Black & 8 & 9 & 8 \\
\hline Other & 6 & 11 & 11 \\
\hline \multicolumn{4}{|l|}{ Cause of end-stage renal disease (\%) } \\
\hline Glomerulonephritis & 30 & 28 & 19 \\
\hline Diabetes & 7 & 9 & 14 \\
\hline Hypertension & 10 & 11 & 4 \\
\hline Repeated transplantation or graft failure & 0 & 1 & 0 \\
\hline Other & 54 & 51 & 63 \\
\hline Deceased donor (\%) & 69 & 73 & 78 \\
\hline Mean duration of cold ischemia (hr) & 20 & 20 & 18 \\
\hline Most recent panel reactive antibody titer $\geq 20 \%(\%)$ & 1 & 3 & 1 \\
\hline$\geq 1$ Prior transplantations (\%) & 1 & 6 & 3 \\
\hline$>3$ HLA mismatches (\%) & 42 & 41 & 40 \\
\hline
\end{tabular}

* Because of rounding, percentages may not total 100 .

$\uparrow \mathrm{P}=0.03$ for the difference among the groups.

Race was self-reported.

of at least grade IIB, requiring use of antilymphocyte antibody preparations, were infrequent in all the groups: 4 percent in the group receiving intensive belatacept, 7 percent in the group receiving lessintensive belatacept, and 3 percent in the cyclosporine group. These instances of rejection were identified whether or not there was a clinical suspicion of rejection. Acute rejection contributed to two graft losses, one in the intensive-therapy group and one in the cyclosporine group. The incidence of secondary end points of biopsy-proven or presumed acute rejection at six months was similar among the groups (11 percent in the intensive-therapy group, 8 percent in the group receiving less-intensive therapy, and 10 percent in the cyclosporine group). Subclinical rejection at month 6 was more common with less-intensive belatacept ( 20 percent) than with intensive belatacept ( 9 percent) or cyclosporine (11 percent) (Table 2). Episodes of subclinical rejection were generally grade IIA or lower and were treated with pulsed doses of corticosteroids.

\section{RENAL FUNCTION}

The measured glomerular filtration rate at 12 months was significantly higher among patients receiving the intensive and less-intensive belatacept regimens than among those receiving cyclosporine $\left(66.3,62.1\right.$, and $53.5 \mathrm{ml}$ per minute per $1.73 \mathrm{~m}^{2}$, respectively; $\mathrm{P}=0.01$ for the comparison between intensive belatacept and cyclosporine and $\mathrm{P}=0.04$ between less-intensive belatacept and cyclosporine) (Table 3). The Modification of Diet in Renal Disease method of estimating the glomerular filtration rate provided the best correlations between measured and calculated rates $(\mathrm{r}=0.58)$.

\section{RENAL HISTOLOGIC FINDINGS}

By month 12, the incidence of chronic allograft nephropathy was lower among patients receiving belatacept than among those receiving cyclosporine: 29 percent in the group receiving intensive belatacept, 20 percent in the group receiving lessintensive belatacept, and 44 percent in the cyclo- 


\begin{tabular}{|c|c|c|c|}
\hline End Point & $\begin{array}{l}\text { Intensive Belatacept } \\
\qquad(\mathrm{N}=74)\end{array}$ & $\begin{array}{l}\text { Less-Intensive Belatacept } \\
\qquad(\mathrm{N}=71)\end{array}$ & $\begin{array}{l}\text { Cyclosporine } \\
(\mathrm{N}=73)\end{array}$ \\
\hline \multicolumn{4}{|l|}{ Primary efficacy end point } \\
\hline $\begin{array}{l}\text { Clinically suspected and biopsy-proven acute } \\
\text { rejection at } 6 \text { mo - no. (\%) }\end{array}$ & $5(7)$ & $4(6)$ & $6(8)$ \\
\hline $\begin{array}{l}\text { Absolute difference in rate from cyclosporine } \\
\text { group - percentage points (exact } 95 \% \mathrm{Cl} \text { )* }\end{array}$ & $-1.5(-11.3$ to 8.3$)$ & $-2.6(-12.3$ to 6.7$)$ & - \\
\hline \multicolumn{4}{|l|}{ Secondary efficacy end points } \\
\hline Mild acute rejection (grade IA) - no. (\%) & $2(3)$ & 0 & $1(1)$ \\
\hline Mild acute rejection (grade IB) — no. (\%) & 0 & 0 & $1(1)$ \\
\hline Moderate acute rejection (grade IIA) — no. (\%) & $2(3)$ & $3(4)$ & $2(3)$ \\
\hline Moderate acute rejection (grade IIB) — no. (\%) & $1(1)$ & $1(1)$ & $2(3)$ \\
\hline Subclinical rejection - no. (\%) & $7(9)$ & $14(20)$ & $8(11)$ \\
\hline $\begin{array}{l}\text { Treated episode of subclinical rejection } \\
\quad-\text { no. (\%) }\end{array}$ & $6(8)$ & $11(15)$ & $5(7)$ \\
\hline
\end{tabular}

$* \mathrm{Cl}$ denotes confidence interval.

sporine group (Table 3). Among patients with chronic allograft nephropathy, the calculated glomerular filtration rate was higher in both belatacept groups than in the cyclosporine group.

\section{PATIENT AND ALLOGRAFT SURVIVAL}

Four patients in the cyclosporine group died, and one patient in the intensive-belatacept group died. Two of the four patients who died in the cyclosporine group died of cardiac causes. Graft loss among the surviving patients was infrequent - occurring in three patients receiving intensive belatacept, one receiving less-intensive belatacept, and two receiving cyclosporine - and was most commonly due to technical reasons, such as renal-vein or renalartery thrombosis (Table 4).

\section{SAFETY}

Safety summaries are based on reports of new or worsening adverse events, as determined by the investigators. Adverse events whose frequency was at least 5 percentage points higher in the cyclosporine group than in either belatacept group included leukopenia, anemia, edema, hypertension, urinary tract infection, hypokalemia, hypomagnesemia, acidosis, tremor, hypertrichosis, and diabetes mellitus (Table 5). Episodes of rejection reported by investigators as an adverse event were the only adverse event whose frequency was at least 5 percentage points higher in both belatacept groups than in the cyclosporine group: 26 percent in the group receiv- ing intensive belatacept, 32 percent in the group receiving less-intensive belatacept, and 16 percent in the cyclosporine group $(\mathrm{P}=0.06)$. Some suspected episodes of transplant rejection included in this analysis were later determined by adjudication not to represent actual episodes of acute rejection. The events confirmed by adjudication were included in the primary efficacy analysis, which showed similar rates of acute rejection in the three groups (Table 2). To date, no clinically significant adverse events had been reported during infusions of belatacept either in the original trial or during follow-up.

The frequency of infection was similar among the groups: 73 percent in both belatacept groups and 75 percent in the cyclosporine group. The most common were urinary tract infections (23 percent in the group receiving intensive therapy, 24 percent in the group receiving less-intensive therapy, and 31 percent in the cyclosporine group) and cytomegalovirus infections (15 percent, 14 percent, and 18 percent, respectively).

Cancer occurred in two patients treated with intensive belatacept (one had breast cancer, and one had post-transplantation lymphoproliferative disorder) and in two patients treated with cyclosporine (one had skin cancer, and one had thyroid cancer). However, post-transplantation lymphoproliferative disorder developed in two additional patients treated with the intensive regimen 2 and 13 months after belatacept had been replaced with convention- 


\begin{tabular}{|c|c|c|c|}
\hline End Point & Intensive Belatacept & $\begin{array}{l}\text { Less-Intensive } \\
\text { Belatacept }\end{array}$ & Cyclosporine \\
\hline \multicolumn{4}{|l|}{ Measured GFR } \\
\hline No. of patients & 32 & 37 & 27 \\
\hline Mean GFR - ml/min $/ 1.73 \mathrm{~m}^{2} \uparrow$ & $66.3 \pm 20.7$ & $62.1 \pm 15.9$ & $53.5 \pm 16.4$ \\
\hline $\begin{array}{l}\text { Difference from cyclosporine group } \\
\quad-\mathrm{ml} / \mathrm{min} / 1.73 \mathrm{~m}^{2}(95 \% \mathrm{Cl})\end{array}$ & 12.8 (2.9 to 22.7$)$ & $8.6(0.4$ to 16.8$)$ & - \\
\hline \multicolumn{4}{|l|}{ Chronic allograft nephropathy } \\
\hline No. of patients & 52 & 54 & 45 \\
\hline CAN at $12 \mathrm{mo}-$ no. $(\%[95 \% \mathrm{Cl}]) \div$ & 15 (29 [16.5 to 41.2$])$ & 11 (20 [9.6 to 31.1$])$ & $20(44[29.0$ to 59.0$])$ \\
\hline Mild CAN (stage I) — no. (\%) & $11(21)$ & $6(11)$ & $16(36)$ \\
\hline Moderate CAN (stage II) - no. (\%) & $4(8)$ & $1(2)$ & $3(7)$ \\
\hline Severe CAN (stage III) — no. (\%) & 0 & $4(7)$ & $1(2)$ \\
\hline $\begin{array}{l}\text { Absolute difference in rate from cyclosporine } \\
\text { group - percentage points (asymptotic } \\
\text { exact } 95 \% \mathrm{Cl} \text { ) }\end{array}$ & $-15.6(-34.6$ to 3.4$)$ & $-24.1(-42.1$ to 6.0$)$ & - \\
\hline \multicolumn{4}{|l|}{ Calculated GFR } \\
\hline No. of patients & 60 & 59 & 50 \\
\hline Mean GFR $-\mathrm{ml} / \mathrm{min} / 1.73 \mathrm{~m}^{2}$ & $72.4 \pm 22.5$ & $73.2 \pm 22.5$ & $68.0 \pm 28.1$ \\
\hline $\begin{array}{l}\text { Difference from cyclosporine group } \\
\quad-\mathrm{ml} / \mathrm{min} / 1.73 \mathrm{~m}^{2}(95 \% \mathrm{Cl})\end{array}$ & $4.4(-5.2$ to 14.0$)$ & $5.2(-4.4$ to 14.8$)$ & - \\
\hline No. of patients without CAN & 49 & 50 & 37 \\
\hline Mean GFR - $\mathrm{ml} / \mathrm{min} / 1.73 \mathrm{~m}^{2}$ & $75.9 \pm 21.3$ & $73.2 \pm 19.8$ & $76.6 \pm 24.4$ \\
\hline $\begin{array}{l}\text { Difference from cyclosporine group } \\
\qquad-\mathrm{ml} / \mathrm{min} / 1.73 \mathrm{~m}^{2}(95 \% \mathrm{Cl})\end{array}$ & $-0.7(-10.5$ to 9.1$)$ & $-3.4(-12.8$ to 6.0$)$ & - \\
\hline No. of patients with CAN & 11 & 9 & 13 \\
\hline Mean GFR - $\mathrm{ml} / \mathrm{min} / 1.73 \mathrm{~m}^{2}$ & $56.9 \pm 22.2$ & $73.1 \pm 35.9$ & $43.6 \pm 23.5$ \\
\hline $\begin{array}{l}\text { Difference from cyclosporine group } \\
\qquad-\mathrm{ml} / \mathrm{min} / 1.73 \mathrm{~m}^{2}(95 \% \mathrm{Cl})\end{array}$ & $13.3(-6.2$ to 32.8$)$ & $29.5(3.2$ to 55.8$)$ & - \\
\hline \multicolumn{4}{|c|}{$\begin{array}{l}* \text { Plus-minus values are means } \pm \text { SD. GFR denotes glomerular filtration rate, } \mathrm{Cl} \text { confidence interval, and CAN chronic al- } \\
\text { lograft nephropathy. } \\
\uparrow P<0.05 \text { for the comparison of both belatacept regimens with cyclosporine. } \\
\downarrow \text { Patients in this group underwent at least one biopsy after baseline. }\end{array}$} \\
\hline
\end{tabular}

al immunosuppressive agents (tacrolimus, mycophenolate mofetil, and corticosteroids). Of the three patients in whom post-transplantation lymphoproliferative disorder developed, two had primary Epstein-Barr virus infections. The third had received a 10-day course of muromonab-CD3 for acute rejection, and belatacept had been discontinued just before this therapy was administered; post-transplantation lymphoproliferative disorder was diagnosed 13 months later. Approximately half the patients were enrolled voluntarily in a long-term extension of the protocol; no additional cases of post-transplantation lymphoproliferative disorder were reported among patients treated for up to four years with belatacept.

\section{CARDIOVASCULAR AND METABOLIC EFFECTS}

At 12 months, the mean ( $\pm S D$ ) total cholesterol levels were similar among the groups, at $198 \pm 41 \mathrm{mg}$ per deciliter ( $5 \pm 1 \mathrm{mmol}$ per liter) in the group receiving intensive belatacept, $201 \pm 40 \mathrm{mg}$ per deciliter ( $5 \pm 1 \mathrm{mmol}$ per liter) in the group receiving lessintensive belatacept, and $212 \pm 44 \mathrm{mg}$ per deciliter ( $5 \pm 1 \mathrm{mmol}$ per liter [ $1 \pm 0 \mathrm{mmol}$ per liter]) in the cyclosporine group. Mean levels of high-density lipoprotein cholesterol were also similar among the groups $(53 \pm 16 \mathrm{mg}$ per deciliter $[1.4 \pm 0.4 \mathrm{mmol}$ per liter] in the group receiving intensive belatacept, $56 \pm 14 \mathrm{mg}$ per deciliter $[1.4 \pm 0.4 \mathrm{mmol}$ per liter] in the group receiving less-intensive belatacept, and $59 \pm 18 \mathrm{mg}$ per deciliter $[1.5 \pm 0.5 \mathrm{mmol}$ 


\begin{tabular}{|c|c|c|c|}
\hline Variable & $\begin{array}{l}\text { Intensive Belatacept } \\
\qquad(\mathrm{N}=\mathbf{7 4})\end{array}$ & $\begin{array}{l}\text { Less-Intensive Belatacept } \\
\qquad(\mathrm{N}=71)\end{array}$ & $\begin{array}{l}\text { Cyclosporine } \\
(\mathrm{N}=73)\end{array}$ \\
\hline \multicolumn{4}{|l|}{ Death at $12 \mathrm{mo}$} \\
\hline Total - no. (\%) & $1(1)$ & 0 & $4(5)$ \\
\hline \multicolumn{4}{|l|}{ Reason - no. (\%) } \\
\hline Cardiac causes & 0 & 0 & $2(3)$ \\
\hline Infection or sepsis & $1(1)$ & 0 & 0 \\
\hline Pulmonary embolism & 0 & 0 & $1(1)$ \\
\hline Other or unknown & 0 & 0 & $1(1)$ \\
\hline \multicolumn{4}{|l|}{ Graft loss at $12 \mathrm{mo}$} \\
\hline Total - no. (\%) & $3(4)$ & $1(1)$ & $2(3)$ \\
\hline \multicolumn{4}{|l|}{ Reason - no. (\%) } \\
\hline Renal-vein or renal-artery thrombosis & $1(1)$ & $1(1)$ & $2(3)$ \\
\hline Infarction $†$ & $1(1)$ & 0 & 0 \\
\hline Treatment of PTLD & $1(1)$ & 0 & 0 \\
\hline Combinationtr & 0 & 0 & $1(1)$ \\
\hline \multicolumn{4}{|l|}{ Death or graft loss at $12 \mathrm{mo}$} \\
\hline Total - no. (\%) & $4(5)$ & $1(1)$ & $6(8) \int$ \\
\hline $\begin{array}{c}\text { Absolute difference from cyclosporine group } \\
\text { — percentage points }(95 \% \mathrm{Cl})\end{array}$ & $-2.8(-11.0$ to 5.3$)$ & $-6.8(-13.7$ to 0.1$)$ & - \\
\hline
\end{tabular}

* $\mathrm{Cl}$ denotes confidence interval, and PTLD post-transplantation lymphoproliferative disorder.

$\dagger$ The cause of infarction was unknown but may have been indicative of ongoing rejection.

Patients may have had a combination of persistent delayed graft function, acute rejection, and infection.

$\int$ One patient had graft loss and subsequently died.

per liter] in the cyclosporine group), as were the mean levels of low-density lipoprotein cholesterol $(145 \pm 37 \mathrm{mg}$ per deciliter $[4 \pm 1 \mathrm{mmol}$ per liter], $144 \pm 36 \mathrm{mg}$ per deciliter $[4 \pm 1 \mathrm{mmol}$ per liter], and $151 \pm 43 \mathrm{mg}$ per deciliter [ $4 \pm 1 \mathrm{mmol}$ per liter], respectively). However, more patients in the cyclosporine group than in either belatacept group were receiving lipid-lowering medications (53 percent, as compared with 36 percent in the intensive-therapy group and 32 percent in the group given lessintensive therapy; $\mathrm{P}=0.03$ for the comparison with both belatacept groups).

Systolic blood pressure at 12 months was 3 or $4 \mathrm{~mm} \mathrm{Hg}$ higher among patients receiving cyclosporine than among patients receiving belatacept, whereas diastolic blood pressure levels were similar among the groups. A post hoc analysis of the prevalence of hypertension requiring treatment at 12 months was 88 percent in the intensive-belatacept group, 83 percent in the group receiving lessintensive belatacept, and 92 percent in the cyclosporine group. Diabetes mellitus was infrequent after transplantation, occurring in 12 percent of pa- tients in the group receiving intensive therapy, 6 percent of those in the group receiving less-intensive therapy, and 12 percent of those in the cyclosporine group.

\section{I SCUSSION}

The primary objective of this study was to demonstrate the noninferiority of belatacept over cyclosporine with respect to the incidence of acute rejection at six months. Our results suggest that the two agents are similarly effective for the prevention of acute rejection. Patients treated with belatacept regimens had rates of acute rejection similar to those among patients taking cyclosporine, satisfying prespecified criteria for noninferiority. The observed rates of acute rejection of 6 to 7 percent with belatacept, mycophenolate mofetil, corticosteroids, and basiliximab in this trial compare favorably with rates of 8 to 17 percent reported in clinical trials of cyclosporine, mycophenolate mofetil, corticosteroids, and basiliximab ${ }^{20-22}$ and are lower than the rate of 47 percent reported in a clinical trial of my- 


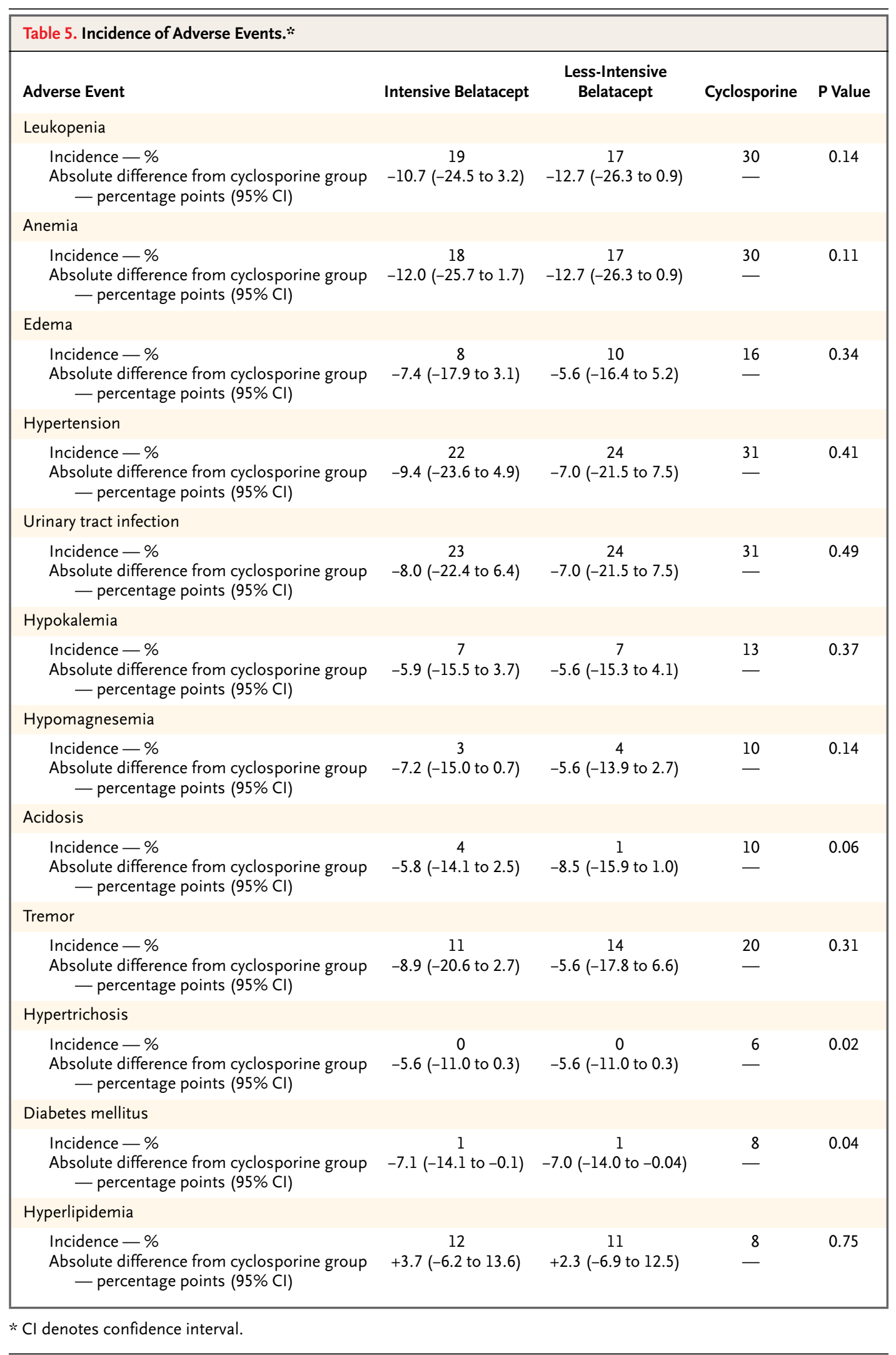


cophenolate mofetil, corticosteroids, and daclizumab in low-risk transplant recipients. ${ }^{23}$

Our results imply that the use of belatacept may allow patients to avoid the adverse renal, cardiovascular, and metabolic effects of cyclosporine. The measured glomerular filtration rate at one year was approximately 9 to $13 \mathrm{ml}$ per minute higher among recipients of belatacept than among cyclosporine recipients. Since the glomerular filtration rate generally declines by approximately $3 \mathrm{ml}$ per minute per $1.73 \mathrm{~m}^{2}$ per year in transplant recipients, these differences, if sustained, could result in improved allograft survival of three to four years. ${ }^{24}$ Underscoring the potential benefit of non-nephrotoxic therapy, we found differences in the calculated glomerular filtration rate favoring belatacept in patients with chronic allograft nephropathy. Measured cholesterol levels and blood pressure were similar or slightly lower in the belatacept groups than in the cyclosporine group, despite the greater use of lipid-lowering and antihypertensive therapy among patients receiving cyclosporine.

Long-term immunosuppression increases the risks of infection and cancer. We found a similar rate of infections among the groups. Likewise, the frequency of cancer was similar, occurring in 2 of 145 patients in the belatacept groups during treatment ( 1 percent) and 4 of 145 overall ( 3 percent) and 2 of 71 patients in the cyclosporine group (3 percent). The rate of cancer with belatacept was consistent with the estimated incidence of 3.3 percent for nondermatologic cancers at one year in the transplantation population. ${ }^{25}$ Cancers appeared to occur in the belatacept groups in a dose-dependent fashion, as has previously been reported with cyclosporine-based regimens. ${ }^{26}$ There were three cases of post-transplantation lymphoproliferative disorder, a well-recognized complication of organ transplantation with reported incidence rates of 0.3 to 1.4 percent in registries and large clinical series $^{27,28}$ and up to 2.9 percent in large, multicenter trials of approved immunosuppressive regimens. ${ }^{29}$ All cases of post-transplantation lymphoproliferative disorder were associated with either primary Epstein-Barr virus infection or treatment with muromonab-CD3, both of which are known risk factors for the disorder. ${ }^{30,31}$ Two cases occurred after the discontinuation of belatacept; it is not possible to determine whether these cases reflect remote effects of belatacept, the effect of immunosuppressive agents that replaced it, or a combination of the two. The occurrence of post- transplantation lymphoproliferative disorder in patients receiving the intensive, but not the lessintensive, regimen of belatacept is also consistent with the experience in other phase 2 immunosuppressive trials, ${ }^{32}$ in which post-transplantation lymphoproliferative disorder was related to the levels of immunosuppression. ${ }^{33} \mathrm{~A}$ long-term, open-label extension of our trial is being conducted, and patients have been treated with belatacept for up to four years, and no additional cases of post-transplantation lymphoproliferative disorder have been reported to date.

Subclinical rejection was found more often among patients receiving the less-intensive regimen of belatacept than among those receiving either intensive belatacept therapy or cyclosporine. The findings in the literature concerning the clinical significance of subclinical rejection are inconclusive. ${ }^{34}$ In our study, subclinical rejection did not appear to have an adverse effect on graft survival, renal function, or the risk of chronic allograft nephropathy in the group receiving less-intensive therapy.

The differences we identified between belatacept and cyclosporine therapy should be regarded as suggestive rather than definitive. Two specific issues in the design and conduct of this study should be noted. First, although prespecified criteria for noninferiority were met and acute rejection was less common with belatacept than with cyclosporine, the noninferiority bounds were relatively broad. Owing to the partially blinded trial design, renal-biopsy specimens were obtained approximately 10 percent more frequently among patients assigned to belatacept than among patients assigned to cyclosporine, a difference that may have biased biopsy-based evaluations against belatacept to some degree.

Second, because of a substantial amount of missing data on the measured glomerular filtration rate, findings of improved renal function with belatacept should be regarded as preliminary. Measurement of the glomerular filtration rate with the use of reference methods (renal clearance or rate of disappearance from plasma) is time consuming and difficult. ${ }^{35}$ Several formulas were used to estimate the glomerular filtration rate on the basis of serum creatinine levels, since this information was more consistently available.

Belatacept is administered intermittently by infusion, in contrast to calcineurin inhibitors, which are administered orally each day. Although the ad- 
ministration of monthly infusions requires monthly visits to a treatment center, it may lead to improved compliance, since nonadherence to the belatacept regimen becomes obvious when the first appointment is missed.

Improved preservation of renal function has been reported with the use of sirolimus- or mycophenolate-based regimens in which cyclosporine is withdrawn early. ${ }^{36-38}$ Unlike the belatacept regimens we used, in these other studies, concurrent use of cyclosporine was required for two to four months, then withdrawn in patients meeting the study criteria of a low-to-moderate immunologic risk of rejection. Belatacept therapy does not require concurrent cyclosporine therapy and has no restrictions based on a predefined immunologic risk of rejection. Other studies evaluated calcineurin-free regimens combining sirolimus and mycophenolate mofetil. ${ }^{38}$ Although these studies showed preservation of renal function, they also found a range of rates of initial rejection and, in one study, more severe rejection or were complicated by high dropout rates, limiting the application of these results. ${ }^{39,40}$

Belatacept represents a new class of primary immunosuppressants, arguably the first since the introduction of cyclosporine, the first calcineurin inhibitor. Whereas calcineurin inhibitors block or diminish the effects of T-cell activation on allografts, belatacept prevents T-cell activation. This effect is accomplished without concurrent global immunosuppression of T-cell-depletion strategies. Our results suggest that belatacept can provide a level of immunosuppressive efficacy in renal-transplant recipients similar to that afforded by cyclosporine, but with the potential benefits of improved cardiovascular and metabolic risk profiles, greater preservation of kidney function, and a lower incidence of chronic allograft nephropathy.

\section{Supported by Bristol-Myers Squibb.}

Dr. Vincenti reports having received support for this investigational protocol from Bristol-Myers Squibb (BMS IM 103-100) and research grants from Roche, Novartis, Genentech, Wyeth, and XdX. Dr. Larsen reports having received consulting fees from BristolMyers Squibb, Pfizer, and Abbott and grant support from BristolMyers Squibb, Novartis, and Abegenix and assigning all future royalties related to U.S. patent "Methods for inhibiting an immune response by blocking the GP39/CD40 and CTLA4/CD28/B7 pathways and compositions for use therewith" $(5,916,560)$, issued jointly to Bristol-Myers Squibb and Emory University, to Emory University. Dr. Wekerle reports having received consulting fees from BristolMyers Squibb and Novartis, speakers' fees from Wyeth-Ayerst, and grants from Novartis, the Austrian National Bank Research Fund, Biomay, and the Roche Organ Transplant Research Fund. Dr. Nashan reports having received consulting fees from Syreon and Novartis and speakers' fees from Novartis and Hoffmann-La Roche. Dr. Lang reports having received speakers' fees from Bristol-Myers Squibb. Dr. Grinyo reports having received consulting and speakers' fees from Bristol-Myers Squibb. Dr. Halloran reports having received grant support from a Roche-Canada Post-Doctoral Fellowship, a Fujisawa Post-Doctoral Fellowship, and the Roche Organ Transplant Research Fund. Dr. Solez reports having received speakers' fees from Wyeth-Ayerst. Drs. Hagerty, Levy, Zhou, and Natarajan are all employees of Bristol-Myers Squibb, and all report equity holding in Bristol-Myers Squibb. Dr. Hagerty reports being listed as one of the inventors in a U.S. patent pending for CTLA4Ig fusion proteins to Bristol-Myers Squibb.

A P PENDIX

In addition to the authors, the following persons were members of the Belatacept Study Group: Austria: F. Muehlbacher, B. Watschinger, R. Margreiter, and C. Bösmüller; Belgium: Y. Vanrenterghem, J.-P. Squifflet, and D.C. Eddour; France: F. Kriaa and J.-P. Soulillou; Germany: J. Klempnauer and F. Hellfritz; Italy: P. Berloco and M. Iapelli; Spain: D. Sercon-Micas; J.M. Morales, and A. Andrés; United Kingdom: P. Friend and P. Mason; Canada: S. Paraskevas, J. Shapiro, and J. Zaltzman; United States: J. Burdick, K. Rice, A.B. Cosimi, J. Bromberg, P.R. Rajagopalan, S. Steinberg, L.T. Chin, R.B. Stevens, C. Barker, S. Mulgaonkar, and M. Stegall.

\section{REFERENCES}

1. Wolfe RA, Ashby VB, Milford EL, et al. Comparison of mortality in all patients on dialysis, patients on dialysis awaiting transplantation, and recipients of a first cadaveric transplant. N Engl J Med 1999;341:172530.

2. Port FK, Wolfe RA, Mauger EA, Berling DP, Jiang K. Comparison of survival probabilities for dialysis patients vs cadaveric renal transplant recipients. JAMA 1993;270: 1339-43.

3. Evans RW, Manninen DL, Garrison LP Jr, et al. The quality of life of patients with end-stage renal disease. N Engl J Med 1985; 312:553-9.

4. Russell JD, Beecroft ML, Ludwin D, Churchill DN. The quality of life in renal transplantation - a prospective study. Transplantation 1992;54:656-60.

5. United Network for Organ Sharing Renal Transplant Registry 2003. (Accessed July 29, 2005, at http://www.unos.org.)

6. Burdmann EA, Andoh TF, Yu L, Bennett WM. Cyclosporine nephrotoxicity. Semin Nephrol 2003;23:465-76.

7. Miller LW. Cardiovascular toxicities of immunosuppressive agents. Am J Transplant 2002;2:807-18

8. Ojo AO, Hanson JA, Wolfe RA, Leichtman AB, Agodoa LY, Port FK. Long-term survival in renal transplant recipients with graft function. Kidney Int 2000;57:307-13.

9. Nankivell BJ, Borrows RJ, Fung CL, O'Connell PJ, Allen RD, Chapman JR. The natural history of chronic allograft nephropathy. N Engl J Med 2003;349:2326-33.

10. Sayegh MH, Turka LA. The role of T-cell costimulatory activation pathways in transplant rejection. N Engl J Med 1998;338:181321.

11. Kremer JM, Westhovens R, Leon M, et al. Treatment of rheumatoid arthritis by selective inhibition of T-cell activation with fusion protein CTLA4Ig. N Engl J Med 2003; 349:1907-15.

12. Abrams JR, Kelley SL, Hayes E, et al. Blockade of $\mathrm{T}$ lymphocyte costimulation with cytotoxic T lymphocyte-associated antigen 4-immunoglobulin (CTLA4Ig) reverses the cellular pathology of psoriatic plaques, including the activation of keratinocytes, 
dendritic cells, and endothelial cells. J Exp Med 2000;192:681-94.

13. Linsley PS, Greene JL, Brady W, Bajorath J, Ledbetter JA, Peach R. Human B7-1 (CD80) and B7-2 (CD86) bind with similar avidities but distinct kinetics to CD28 and CTLA-4 receptors. Immunity 1994;1:793-801. [Erratum, Immunity 1995;2:following 203.]

14. Larsen CP, Pearson TC, Adams AB, et al Rational development of LEA29Y (belatacept), a high-affinity variant of CTLA4-Ig with potent immunosuppressive properties. Am J Transplant 2005;5:443-53.

15. Racusen LC, Solez K, Colvin RB, etal. The Banff 97 working classification of renal allograft pathology. Kidney Int 1999;55:713-23. 16. Levey AS, Bosch JP, Lewis JB, Greene T, Rogers N, Roth D. A more accurate method to estimate glomerular filtration rate from serum creatinine: a new prediction equation. Ann Intern Med 1999;130:461-70.

17. Jelliffe RW. Creatinine clearance: bedside estimate. Ann Intern Med 1973;79: 604-5.

18. Cockcroft DW, Gault MH. Prediction of creatinine clearance from serum creatinine. Nephron 1976;16:31-41.

19. Nankivell BJ, Gruenewald SM, Allen RD, Chapman JR. Predicting glomerular filtration rate after kidney transplantation. Transplantation 1995;59:1683-9.

20. Kode R, Fa K, Chowdhury S, et al. Basiliximab plus low-dose cyclosporin vs. OKT for induction immunosuppression following renal transplantation. Clin Transplan 2003;17:369-76

21. Lawen JG, Davies EA, Mourad G, et al. Randomized double-blind study of immunoprophylaxis with basiliximab, a chimeric anti-interleukin-2 receptor monoclonal antibody, in combination with mycophenolate mofetil-containing triple therapy in renal transplantation. Transplantation 2003;75 37-43.

22. Lebranchu Y, Bridoux F, Buchler M, et al. Immunoprophylaxis with basiliximab compared with antithymocyte globulin in renal transplant patients receiving MMF-containing triple therapy. Am J Transplant 2002;2 48-56.

23. Vincenti F, Ramos E, Brattstrom C, et al. Multicenter trial exploring calcineurin in hibitors avoidance in renal transplantation. Transplantation 2001;71:1282-7.

24. Gaspari F, Ferrari S, Stucchi N, et al. Per formance of different prediction equations for estimating renal function in kidney transplantation. Am J Transplant 2004;4:1826-35. 25. Kasiske BL, Snyder JJ, Gilbertson DT, Wang C. Cancer after kidney transplantation in the United States. Am J Transplan 2004;4:905-13.

26. Dantal J, Hourmant M, Cantarovich D, et al. Effect of long-term immunosuppression in kidney-graft recipients on cancer incidence: randomised comparison of two cyclosporin regimens. Lancet 1998;351:623-8. 27. Opelz G, Dohler B. Lymphomas after solid organ transplantation: a collaborative transplant study report. Am J Transplan 2004;4:222-30.

28. Boubenider S, Hiesse C, Goupy C, Kriaa F, Marchand S, Charpentier B. Incidence and consequences of post-transplantation lymphoproliferative disorders. J Nephrol 1997 10:136-45.

29. Jensik SC. Tacrolimus (FK 506) in kidney transplantation: three-year survival results of the US multicenter, randomized, comparative trial. Transplant Proc 1998;30:1216-8.

30. Walker RC, Paya CV, Marshall WF, et al. Pretransplantation seronegative Epstein-Bar virus status is the primary risk factor fo posttransplantation lymphoproliferative disorder in adult heart, lung, and other solid organ transplantations. J Heart Lung Transplant 1995;14:214-21.

31. Swinnen LJ, Costanzo-Nordin MR, Fisher SG, et al. Increased incidence of lymphoproliferative disorder after immunosuppression with the monoclonal antibody OKT3 in cardiac-transplant recipients. $\mathrm{N}$ Engl J Med 1990;323:1723-8.

32. Amlot PL, Rawlings E, Fernando ON, et al. Prolonged action of a chimeric interleukin-2 receptor (CD25) monoclonal antibody used in cadaveric renal transplantation. Transplantation 1995;60:748-56.

33. Herzig KA, Juffs HG, Norris D, et al A single-centre experience of post-renal transplant lymphoproliferative disorder. Transpl Int 2003;16:529-36.

34. Nankivell BJ, Borrows RJ, Fung CL, O'Connell PJ, Allen RD, Chapman JR. Natural history, risk factors, and impact of subclinical rejection in kidney transplantation. Transplantation 2004;78:242-9.

35. Gaspari F, Perico N, Remuzzi G. Application of newer clearance techniques for the determination of glomerular filtration rate. Curr Opin Nephrol Hypertens 1998;7:675-

36. Abramowicz D, Mamas D, Lao M, et al. Cyclosporine withdrawal from a mycophenolate mofetil-containing immunosuppressive regimen in stable kidney transplant recipients: a randomized, controlled study. Transplantation 2002;74:1725-34.

37. Johnson RWG, Kreis H, Oberbauer R, Brattstrom C, Claesson K, Eris J. Sirolimus allows early cyclosporine withdrawal in renal transplantation resulting in improved renal function and lower blood pressure. Transplantation 2001;72:777-86.

38. Flechner SM, Kurian SM, Solez K, et al. De novo kidney transplantation without use of calcineurin inhibitors preserves renal structure and function at two years. Am J Transplant 2004;4:1776-85.

39. Kreis H, Cisterne JM, Land W, et al. Sirolimus in association with mycophenolate mofetil induction for the prevention of acute rejection in renal allograft recipients. Transplantation 2000;69:1252-80.

40. Pescovitz M, Vincenti F, Hart M, et al. Pharmacokinetics, safety and efficacy of mycophenolate mofetil in combination with sirolimus vs. cyclosporine in renal transplant patients. Am J Transplant 2004;4:Suppl 8 251. abstract.

Copyright @ 2005 Massachusetts Medical Society.

\section{CLINICAL TRIAL REGISTRATION}

The Journal encourages investigators to register their clinical trials in a public trials registry. The members of the International Committee of Medical Journal Editors plan to consider clinical trials for publication only if they have been registered (see N Engl J Med 2004;351:1250-1). The National Library of Medicine's www.clinicaltrials.gov is a free registry, open to all investigators, that meets the committee's requirements. 